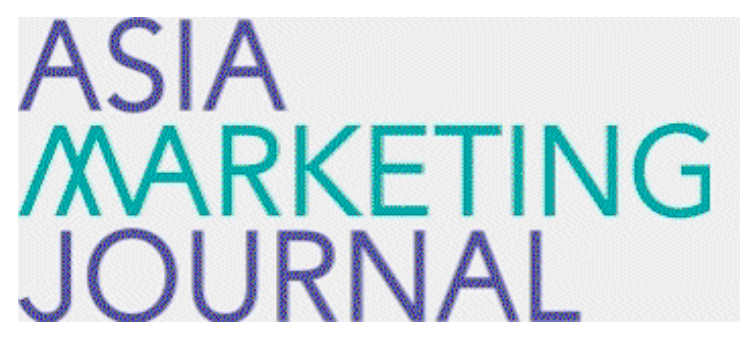

ASIA MARKETING JOURNAL

Volume 18 | Issue 4

Article 5

$1-31-2017$

\title{
Shiraz Vs Syrah Crafting Advertising Campaign, using Sensory Images
}

Kyoung Sung Choi

Follow this and additional works at: https://amj.kma.re.kr/journal

Part of the Marketing Commons

\section{Recommended Citation}

Choi, Kyoung Sung (2017) "Shiraz Vs Syrah Crafting Advertising Campaign, using Sensory Images," Asia Marketing Journal: Vol. 18 : Iss. 4 , Article 5.

Available at: https://doi.org/10.15830/amj.2017.18.4.99

This Article is brought to you for free and open access by Asia Marketing Journal. It has been accepted for inclusion in Asia Marketing Journal by an authorized editor of Asia Marketing Journal. 


\title{
Shiraz Vs Syrah \\ Crafting Advertising Campaign, using Sensory Images
}

\author{
Kyoung Sung Choi*
}

\begin{abstract}
Little research on sensory study has been conducted from a marketing perspective and most of sensory studies have been done from a science perspective. Thus, this study examined wine sensory perceptions in the consumers' minds, which is how wine consumers associate grape variety Shiraz/ Syrah by the three different region of origins with specific sensory images. Total 234 questionnaires were collected from online wine community members at restaurants in Korea. The main results show that the most two shared sensory images of Shiraz/ Syrah were 'Dry' and 'Fruity' across the three region of origins. For Barossa Shiraz, the unique images were mainly found in Aroma image category such as 'Chocolate', 'Prune', whereas for Rhone Syrah, the unique images were mainly revealed in Overall image category e.g. 'Deep', 'Fascinating'. Additionally, this study confirmed that Maipo Valley is not recognizable region of origin of Shiraz/ Syrah. This study employed a free choice, Pick Any and conducted correspondence analysis to find out the degree of associations of sensory images and each region of origin.
\end{abstract}

Key words: Correspondence Analysis, Sensory Image, Region of Origin, Pick Any

\section{Introduction}

Despite the economic downturn, wine demand in South Korea (hereafter, Korea) has increased steadily in the coming years as healthy and trendy lifestyle but Korea still belongs to the emerging wine market (USDA, 2016). We know these emerging markets are growing substantially and present new challenges for marketers. Given the emerging stage of the Korean wine market, marketers should drive more active promotion and advertising efforts. However, considering the actual marketing environment, in which consumers are bombarded with an ever - increasing advertising messages everywhere and pay little

\footnotetext{
* PhD Student Department of Foodservice Management, College of Hospitality \& Tourism Management, Sejong University (kyoungforever@hotmail.com), Corresponding Author
} 
attention to much of which are exposed (Romaniuk, 2003). For this reason, wine marketers are also under increasing pressure to develop advertising campaigns that can appeal to consumers' minds and eyes. Due to the fact that sensory images play a vital role in wine choices, the key campaign messages could be associated with sensory images, effectively characterizing the sensory perceptions of wine consumers. Regarding of sensory aspect of wine, most of past research has been heavily based on wine experts from wine science perspective. Therefore, there is a strong need to engage in a sensory study, based on wine consumers from a marketing perspective. The ultimate goal of this paper is to examine which sensory images can be better for developing advertising campaign of Shiraz/ Syrah by three different ROOs among Korean wine consumers. A literature review starts with brand image associations, in order to apply theoretical base of brand image associations into the present study. Further, this study discusses how sensory images can be utilized for wine advertising campaigns. Then this study presents research methodology used to assess the sensory image associated with Shiraz/ Syrah across the three ROOs and the sampling method. After the main findings, this study concludes with a discussion of the findings and their market implications for advertising campaigns, using Shiraz/ Syrah sensory images.

\section{Literature Review}

\subsection{Brand Associations for Advertising Campaign}

The perceptions possessed by consumers about brands are referred to overall as the brand image, which is made up of the network or schema of attributes connected to the brand (Keller, 1993). Brand images are also used to determine the position of the brand and assess the effectiveness of brand advertising (Dillon et al 2001; Myers 2003). Brand images are essentially residual traces of past brand usage experiences. Brand images are the perceptions of a particular brand that consumers store in their minds and use in purchasing situations, and brand associations are the results of this process. Brand associations were originally on the basis of Associative Network Theories (ANT) of memory, one of the theories most broadly applied to marketing (Anderson and Bower, 1979) and ANT explains that attributes in memory are comprised of concept that is linked together in a network. Importantly, marketers should find out these attributes and then develop campaign messages focusing solely on those attributes. In a same manner, applying brand associations theory into the present study design, this study also decided to discover 'these attributes' of grape variety Shiraz/ Syrah, and then this study can create advertising campaign messages for Shiraz/ 
Syrah. On the one hand, particularly in wine market research, there have been few studies that have specifically examined wine brand images using brand associations theory. Indeed, much previous research (Bourdeaux and Palmer, 2007; Orth and Malkewitz, 2006; Elliot and Barth, 2012) has been concentrated on wine label design or wine packaging issues, using an aesthetic approach, to measure wine brand images. In fact, there have been only a few attempt to investigate regional wine brand image (Johnson and Bruwer, 2007), based on brand associations theory. Johnson and Bruwer have found that the mental associations of Sonoma County images stand in stark contrast to the Alameda county images that store in US wine consumers' minds. As well, Remaud and Lockshin (2009) have discussed how a wine regional branding strategy can be designed employing brand association theory. This paper will also examine wine regional brand images using a set of specific sensory images of grape variety Shiraz/ Syrah, measuring brand image associations by three different ROOs; Australia Barossa Valley, Chile Maipo Valley and France Rhone Valley among Korean wine consumers, attempting to set up advertising campaign by ROOs.

\subsection{Unique Association for Key Message}

The need to offer something different from competitors to compete successfully has long been a tenet in marketing. One strategy to achieve brand differentiation is building consumer perceptions of brand uniqueness. Brand uniqueness means that a particular brand is the only brand that a consumer associates with a specific image (e.g. only Coca-Cola is associated with 'refreshing' among beverages) (Meryers - Levy, 1989), in opposition to shared brand associations where several brands are associated with an image (e.g. a consumer perceives both Coca-Cola and Sprite as 'refreshing') (Haley and Baldinger, 1989). Indeed, it is deemed desirable for a brand to have unique associations connected with it in the consumer's mind and also unique brand associations are thought to be more useful than shared brand associations, as they make the purchasing decision process easier and quicker for consumers (Tversky 1972). This is the belief usually taken by most advertising campaigns that seek to build unique associations, therefore this study also utilizes this unique brand association theory in order to find out a key message of advertising campaign of Shiraz/ Syrah. To sum up, this study can argue that a unique mixture of strong associations is essential for creating a successful advertising campaign. Applying the theoretical concept of unique associations versus shared associations into the present study, this study will specifically discover which image attributes have unique/ shared associations by ROOs and leveraging unique versus shared associations of Shiraz/ Syrah, the author can devise the most suitable advertising campaign by three different ROOs. 


\subsection{Wine Regional Brand Image, using Sensory Image}

Wine is one area where origin plays a crucial role, and where wine is viewed as a product coming from a 'place', which can be a region or a country. Particularly, ROO is becoming increasingly important, as there is a growing trend towards the wine consumption with "designation of origin' e.g. country of origin, region of origin. Also, past research (Corsi et al 2012) has highlighted the importance of communicating the ROO of the wine and they recommend that geography is an important factor for a wine selection. Along with the importance of ROO, certainly wine regional brand image is an important research topic to exploit, as consumers are ready to pay much higher prices for wellknown region of wines when consumers are unsure about the quality. So far, a number of studies has illustrated that origin branding continues to be a key selling point for wines in consumer purchasing decision (Perrouty et al., 2007). However, past research has heavily focused on ROO only as one of purchasing cues. Actually the subject of regional branding in wine industry has not been deeply investigated. Even still not enough is known about the brand image perceptions of icons of region of origin such as Bordeaux, Napa Valley, Barossa Valley and so on.

Meanwhile, the globalization of the current wine market shows a strong interest for wines that has a particular defined style based on sensory characteristics such as fruity Shiraz, and some wine regions have been using a grape variety's sensory images to create that regional brand awareness and consumers' share of mind e.g. grassy Marlborough Sauvignon Blanc. Interestingly, it is arguable that wine regional branding may be another name of grape varietal marketing. Indeed most of well - known wine regions are strongly associated with their own particular grape varieties. Besides, grape varietal marketing practice appears to ensure wine regional branding even in export markets, like Asian emerging wine markets (Wine Intelligence, 2011). Most of Korean wine consumers are not familiar to the landscape, heritage, culture, or history of wine regions without visiting those wine regions directly. However, it is highly assumed that they would be better able to know about wine taste itself e.g. aroma, taste, flavor rather than the landscape, history of wine region. Therefore, to create wine regional campaign messages in Korean wine market, this study suggests that the wine regional brand image has to be cultivated with a specific grape variety and need to identify the unique sensory image of grape variety, most associated to the region in the minds of consumers.

\subsection{Regional Campaign for Wine, using Sensory Image}

Previous research has shown that brands can be 'brought to (the consumer's) mind' via many 
types of image and the images cover a variety of different aspects of brands (Romaniuk and Sharp, 2003). Furthermore, any image can be utilized as part of a marketing communications campaign. In the case of wine, the image can include sensory aspects (e.g. fruity, grassy), or quality aspects (e.g. high quality), etc. particularly for wine, sensory image might be the most frequently employed marketing communication tool. A few other industry, including the perfume industry, has undoubtedly developed sensory images which can represent the characteristics of a product in detail, such as sight, smell, touch, and taste (d'Hauteville 2003). Puyares et al (2010) have conducted the effect of the selected wine sensory images which were 'Robust', 'Full', 'Acidic', 'Delicate', 'Dry', 'Astringent,, 'Fresh', 'Light', 'Alcoholic', 'Complex', 'Sweet' and 'Sophisticated'. Besides the wine industry, there have been sensory attribute studies in the yoghurt market (Vickers 1993), the hamburger market (Moskowitz et al 2002) and the soft drink market (Enneking et al 2007). In the wine markets, some wine mass marketers have already devised a stealth branding strategy with logos (Labroo et al 2008), or slogans for promotion and advertising campaign, utilizing sensory images. Interestingly, past research (La Tour et al 2011) has shown that wine novices were heavily influenced by sensory campaign messages while wine experts did not pay attention to those messages. Therefore, it is highly inferable that wine campaign messages should be based on the images in the wine consumers' minds, not in wine experts' mind. Nevertheless, most of previous sensory research heavily has been done from the perspective of wine experts only. Hence, this study will deliver meaningful findings for wine marketers to understand how strategically they can utilize sensory images for marketing communication strategy e.g. wine promotion/ regional/ advertising campaign. In this paper, the author will discover and discuss how sensory image can be designed into a regional advertising campaign for wine of the grape variety, Shiraz/ Syrah by three ROOs.

\section{Research Methodology}

\subsection{Research Questions}

The main research question is how each ROO of Shiraz/ Syrah is positioned on relevant sensory images in comparison to other two competitor Shiraz/ Syrah wine regions. In other words, how differently/ similarly consumers perceive specific sensory images of Shiraz/ Syrah by three different ROOs. The other related questions to which this research sought answers are:

- Are there unique/ shared associations for sensory images of Shiraz/ Syrah by each $\mathrm{ROO}$ ?

- Are there unique/ shared associations for 
each four different type of images of Shiraz/ Syrah; Aroma, Overall, Body, and Sweetness by each ROO?

- How does one ROO Shiraz/ Syrah compare to another? How does this compare to sensory image associations?

- How can sensory images of Shiraz/ Syrah be used to develop a Shiraz/ Syrah's image for each regional wine advertising campaign?

\subsection{Questionnaire Preparation}

A questionnaire in Korean language comprises of three parts: 1) wine involvement scaling; 2) sensory images of Shiraz/ Syrah for Pick Any sorting tasks by the three ROOs. i.e., to check all the sensory images that associate with grape variety i) Shiraz from Barossa Valley in Australia, ii) Syrah From Rhone Valley in France iii) Syrah from Maipo Valley in Chile and 3) wine consumption, expenditure \& demographic questions. The final questionnaire had a total 16 questions of which all were close - ended. An interviewer visited online wine community members' offline regular meetings at restaurants for about two months in Seoul, Korea. Then all the respondents completed their questionnaires before beginning of wine and dining sessions. After each wine and dining session, $1 \sim 2$ bottles of wine were given to members through lucky draws. Next, the author addresses in details why the author chose 'Online wine community' as a representative sample of the present study. Then this study explains the procedures of screening question, non-response bias, wine involvement scaling, choice of variety and ROOs, construction of the sensory images, and the preliminary study.

\subsubsection{Online wine community}

According to GAIN Report (USDA, 2012), online wine community members are actively communicating their ideas and experiences with the general consumers and they largely influence on new wine consumption trends in Korean wine market. Also, online community members have thousands of serious wine consumers and most of them hold lengthy experience and wine knowledge (USDA, 2011). These key wine consumers of Korean wine market are youthful (Wine Intelligence, 2011) and they have much higher exposure to Western culture than their predecessors (USDA, 2012). They are mainly comprised of relatively young professionals 30 - 40's and young Koreans 20 - 30's, developing an interest in wine. Therefore, it is apparent that online wine community members are a highly representative sample of Korean wine consumers as well as highly influential in Korean wine consumption trends. In the present study, total $75 \%$ of respondents were obtained from online wine community members 'Wine \& People', 'Wine \& Network', 'Wine \& joy', 'Wine Café' etc. The rest of the respondents were previously engaged with online wine communities and regular wine drinkers. 


\subsubsection{A screening question}

Online wine community members were asked a screening question "Have you ever drunk or bought wines in the last 1 year?" beforehand to ensure they would be able to fulfill the Pick Any sorting tasks successfully. Here, the author specifies the screening question more in details.

This study did not require the respondents have consumed Shiraz/ Syrah wines or not, because "it does not matter whether respondents have bought or drank Shiraz/ Syrah before or not". Measuring brand image associations, marketers are still interested in understanding the brand associations held by non - buyers, to more fully capture the brand associations from those in the market who do not currently buy the brand (Romaniuk, 2006). For example, both buyers and non - buyers of Benz are likely to associate Mercedes Benz with 'high class' image and are not likely to associate with 'cheap' image. Another example, regardless of drinkers or non - drinkers, both consumers are likely to associate Coca-Cola with 'American' and are not likely to associate with 'a traditional Chinese drink' (Romaniuk and Sharp, 2000). In the same context, even if wine consumers did not consume Shiraz/ Syrah yet, there still would be possibilities for them to have Shiraz/ Syrah image. Here, this study emphasizes that the author intended to measure perceived sensory images in consumers' minds, NOT actual wine sensory characteristics. Considering wine is one of the most personal interest products in food market and the taste itself is varied by each different consumption situations, it is natural that real sensory characteristics, with wine tasting is not the solution of making advertising campaign. Rather measuring sensory images accumulated inside of consumers' minds without wine tasting is the answer.

\subsubsection{Non - response bias}

A total of 234 valid questionnaires were collected. As expected, approximately 10\% of the respondents did not pick up any images of Shiraz/ Syrah across three ROOs. This suggests that $10 \%$ of respondents consumed wines but they did not taste or hear about Shiraz/ Syrah. Perhaps even though they knew about Shiraz/ Syrah, they could not easily think of Shiraz/ Syrah. We have to remember that the Pick Any sorting method is a free response in that respondents can pick up any, all or no images (Driesener and Romaniuk, 2006). Undoubtedly picking up nothing is one type of answer that can be shown at Pick Any sorting tasks. Therefore, for questionnaire design such as this, "attrition and non - response bias is not an issue" (Baranrd et al, 1986; Driesener and Romaniuk, 2006 p.686).

\subsubsection{Wine involvement scaling}

To identify whether there are significant relationships between the number of images that 
come to mind associated with Shiraz/ Syrah by each ROO and the levels of wine involvement or not, this study measured three levels (high, medium, and low) of wine involvement, following statements (Atkin et al 2005) given on a 7 point Likert-scale (1: strongly disagree, 7: strongly agree),

1. I have a strong interest in wine

2. Wine is important to me in my lifestyle

3. Drinking wine gives me pleasure

This study divided three levels of involvement almost evenly. i) below 14 score is categorized as a low involvement group (27.8\%). ii) $14 \sim 17$ score categorized as a medium involvement group (37.6\%). iii) $18 \sim 21$ score is categorized as a high involvement (34.6\%) group.

\subsubsection{Construction of sensory images}

To define the semantic space (grouping of images), this study has been referred to various sources in order to develop a set of sensory images of Shiraz/ Syrah for the Pick Any sorting task. The author principally was referred to wine specialized books such as 'Australian wine styles and tastes', and the 'Wines and Spirits, WSET' textbook. The author sifted through and then picked out all the sensory attributes of Shiraz/ Syrah. Additionally, the author was referred to the wine experts' wine tasting notes used in wine sommelier classes at a university in Korea. Through this process, total of 131 sensory images were selected. According to Romaniuk and Sharp (2004), when designing a list of images, a diverse type should be combined to capture the quantity of the attribute network in the consumers' memory. Thus this study categorized four different types of sensory images, which were comprised of 76 Aroma images, 49 Overall images, 3 Body images and 3 Sweetness images (see Appendix B) of grape variety Shiraz/ Syrah. As all the respondents of this study were Koreans, all the sensory images were professionally translated from English into Korean. This was undertaken to ensure a good understanding of the sensory images and to limit inaccurate data based on the respondent not understanding the sensory images. The questionnaire was pretested twice using a group of wine experts and subsequently revised, omitted and added each time to improve readability.

\subsubsection{The preliminary study}

The preliminary study was carried out over one month through individual face to face interviews. The preliminary study was comprised of a total of 6 Pick Any sorting tasks only, including 3 Aroma and 3 Overall images questions, in the Korean language. One part of questions was Pick Any sorting task for Aroma images of Shiraz/ Syrah by the three ROOs; Australia, France \& Chile. In a same manner, 
the other question part is Overall images of Shiraz/ Syrah. A total of 16 wine experts (see part of list on Appendix A) responded the questionnaires - 9 wine professionals who were constituted of wine sommeliers, wine professors, Korea International Sommelier Association members and wine connoisseurs who had formerly been online wine community leaders in Seoul, Korea. After the preliminary study, with the aim of establishing the main sensory images of Shiraz/ Syrah, the sensory images were reduced to 36 for the main questionnaire part; 16 Aroma, 14 Overall, 3 Sweetness, and 3 Body images. The order of images was randomized to avoid bias in the results. Table 1 summarizes the final 36 sensory images that were selected.

\subsubsection{The choice of variety \& ROO}

The author chose one red wine grape variety 'Shiraz/ Syrah' for this study for the following several reasons. Firstly, the current trend of wine consumption in South Korea is red wine accounted for a $68.5 \%$ of total wine imports in value in 2015 (USDA, 2016). Secondly, among the red wine grape variety, the author believes Shiraz/ Syrah is the suitable grape variety for this study, due to its distinctly balanced distribution of well-known ROOs from both new (Australia, Barossa) and old (France, Rhone) world wine countries (Iland and Gago, 2005; WSET, 2005). Considering the significance of ROO, this study has chosen the two well-known ROOs (Australia Barossa and French Rhone) and a relatively unknown ROO (Chile Maipo)

〈Table 1〉 Sensory images of grape variety 'Shiraz/ Syrah'

\begin{tabular}{l|l|l|l}
\hline \multicolumn{4}{c}{ The 36 sensory images selected from the preliminary study } \\
\hline \multicolumn{1}{c|}{ Aroma (16) } & \multicolumn{1}{|c}{ Overall (14) } & \multicolumn{1}{c}{ Body (3) } & Sweetness (3) \\
\hline black pepper & thick & full & a bit sweet \\
black berry & heavy & medium & dry \\
spice & masculine & \\
spicy & strong & & \\
black currant & characterful & \\
fruity & stately & \\
licorice & deep & \\
oaky & rich & & \\
chocolate & splendid & & \\
prune & distinguish & & \\
leather & robust & & \\
jammy & fascinating & & \\
cedar & bold & & \\
plum & modern & & \\
feral & & & \\
earthy & & & \\
\hline
\end{tabular}


of Shiraz/ Syrah, in order to examine how differently or similarly the respondents associate sensory images with well-known ROOs and the unknown ROO. On the one hand, Australian wines face strong competition from both quality - driven old world suppliers (France) and value - driven new world suppliers (Chile). In addition to this, from a wine science perspective, this study assumed that Australia and Chile have possibility to present a similar New World wine style while Chile and Australia present a dissimilar wine style with Old World wine style, France. With this triangular relationship among Chile-France-Australia, this study employed three ROOs, namely, Australia Barossa Valley, France Rhone Valley, and Chile Maipo Valley.

\subsection{Data Analysis}

To determine the associations between sensory images and ROOs of Shiraz/ Syrah, frequency of mention of each image of the Pick Any question was employed by counting the number of consumers that used those images. Then, correspondence analysis is used to portray two sets of points simultaneously in a joint space (Calantone, di Benedetto, Hakam, \& Bojanic, 1989): ROOs and sensory images of Shiraz/ Syrah.

\subsubsection{Pick any}

The sorting technique has already been ap- plied on a variety of food products research, including red wine (Gawel et al 2001). Some researchers (Faye et al 2004: Lim and Lawless 2005: Cartier et al 2006) have investigated the efficiency of sorting technique, compared to descriptive analysis, to achieve a sensory map of food products. They argued the sorting technique can overcome the problem, in which the application of descriptive analysis remains time inefficiency, due to the vocabulary and associated training. Finally they confirmed that sorting is time - effective, at a time reduction estimated to be 55\% (Driesener and Romaniuk, 2006). As well, since Joyce (1963)' report, The Pick Any sorting technique has been reported to be easier, quicker and more natural to use for participants (Ares et al 2008a). For this reason, this study apply the Pick Any sorting technique in that respondents can link any, all or no sensory images with each ROO of Shiraz/ Syrah. Interestingly, Pick Any technique has been recently introduced to determine which attributes consumers perceive in a food product, namely CATA, or Check-All-That-Apply (Dooley et al 2010).

\subsubsection{Correspondence analysis}

Correspondence analysis has been proposed to use sensory studies (McEwan and Schlich 1992; Torres and Greenacre 2002; Sinesio 2005; Torres and Van de Velden 2007; Panea et al 2009) including the restaurant industry (Berenguer et 
al 2009). It has been argued by advocates that "It is more correct to use correspondence analysis with sensory data due to its often categorical nature." (McEwan and Schlich 1992). In an attempt to accomplish the distinct position for unique associations that differentiate it from competitors (Aaker 1992), in this study correspondence analysis is used to investigate and summarize the associations between three ROOs and thirty six sensory images of Shiraz/ Syrah. By jointly displaying the three ROOs and sensory images, we can readily see the similarities and dissimilarities between them.

\subsection{Sample}

\subsubsection{Demographics}

The majority (87\%) of the respondents were between the ages of $25 \sim 40$; the $25 \sim 28$ age group (16\%), the $29 \sim 34$ age group (45\%), and the 35 40 age group (25\%). While the gender spilt was almost equal, there were slightly more low medium females $(37 \%)$ involved than male $(29 \%)$. The education status of total sample was high, with $89 \%$ in possession of undergraduate qualification and above. Particularly, only $18.2 \%$ of the respondents were married. Interestingly, the polarized distribution of $\mathrm{re}^{-}$ spondents at monthly household income level was revealed to be $26.8 \%$ in the $2,000,000$ $3,000,000 \mathrm{KW}$ 'group and $18.2 \%$ in the 'Over 8,000,000 KW’ group.

\subsubsection{Wine consumption \& expenditure}

Table 2 shows that the average monthly volume consumption of the sample was 5.9 bottles, with the average of males significantly higher than females (at the .001 level, independent samples t-test). The females in this study drink significantly less wine and spent less money

〈Table 2〉 Monthly wine consumption \& expenditure by the respondents

\begin{tabular}{l|c|c}
\hline & $\begin{array}{c}\text { Amount spent } \\
\text { / month(KW) }\end{array}$ & $\begin{array}{c}\text { Consumption } \\
\text { / month (bottles) }\end{array}$ \\
\hline GENDER & 481,481 & 8.25 \\
Male & 158,284 & 3.61 \\
Female & 3.642 & 4.988 \\
t-value & 0.0001 & 0.0001 \\
sig (2-tailed) & & \\
& & \\
INCOME & & \\
< 5,000,000 & 188,093 & 5.2 \\
$\geq 5,000,000$ & 468,659 & 6.5 \\
t-value & 2.841 & 1.287 \\
sig (2-tailed) & 0.006 & 0.2 \\
\hline
\end{tabular}

Notes: Grouping variables: Gender \& Income 
than the males. In terms of monthly wine expenditures, there were found to be significant differences between the below 5,000,000KW groups and the over 5,000,000KW groups, however there were no significant differences between below and over 5,000,000KW groups for wine consumption volume. In addition, there were no significant differences across the age groups in terms of wine consumption and expenditures. In relation of wine drinking frequency (not shown), $61.3 \%$ of low involved, $59 \%$ of medium and $75 \%$ of highly involved respondents drink wine at least once per month, twice per month, and once per week respectively. This might guide the considerable relation between the degree of involvement and wine drinking frequency.

\section{Results \& Discussions}

\subsection{Number of images used in the pick any questions}

Friedman's test was performed on the number of images used by involvement level. Significant differences $(p<0.0001)$ were found in the mean number of images used by the three involvement groups. Therefore, the number of images used to associate Shiraz/ Syrah in the Pick Any questions was a measure of the differences of wine consumers' associations of the sensory images of Shiraz/ Syrah. As shown in Table 3, the highly involved respondents used more images than the medium and low involvement groups, associated with each ROO of Shiraz/ Syrah. This seems to indicate that highly involved respondents have relatively more experience in the capacity to know, taste, and hear about Shiraz/ Syrah than the rest. Not surprisingly, Barossa Shiraz was the most described, coinciding with the fact that Maipo Syrah, the least described, was the one with less images used. From this result, this study might assume that Barossa Valley is better known as ROO of Shiraz among the Korean respondents, due to the distinguishing wine style itself. Or it could be natural that larger portion of Barossa Shiraz is available in Korea than Rhone Syrah; thus consumers could taste Barossa Shiraz more often than Rhone Syrah and they might have clearer knowledge and perception of Barossa Shiraz.

\subsection{Crosstabulation of wine sensory images \& ROOs}

Cross tabulation of frequency (see Table 4) was constructed to determine the bivariate relationship of ROOs and the wine sensory images and to carry out a correspondence analysis on the frequency mention of each wine sensory image for each wine region in the Pick Any question section. As shown in Table 4, 'Fruity' (181) was the most frequently used sensory image 
〈Table 3〉 Mean Number of Sensory images used by Wine Involvement

\begin{tabular}{lcccc}
\hline \multicolumn{5}{c}{ Mean Number of images Used } \\
\hline \hline & $\begin{array}{c}\text { High } \\
\text { Involved } \\
\text { Respondents }\end{array}$ & $\begin{array}{c}\text { Medium } \\
\text { Involved } \\
\text { Respondents }\end{array}$ & $\begin{array}{c}\text { Low } \\
\text { Involved } \\
\text { Respondents }\end{array}$ & Total \\
Barossa & 7.8 & 5.0 & 3.4 & 16.2 \\
Rhone & 6.9 & 4.6 & 3.0 & 14.5 \\
Maipo & 5.9 & 4.4 & 2.6 & 12.9 \\
\hline Total & 20.6 & 14.0 & 9.0 & \\
\hline
\end{tabular}

and the second one was 'Rich' (159) across the three ROOs. Australian Barossa Shiraz had the highest number of frequency (1288) and French Rhone Syrah showed the second highest (1161), while Chile Maipo had the lowest (1034) by all the category of sensory images, except Sweetness category, (Australia: 101, Chile: 82, France: 77). From this finding, it was confirmed again that Australia Barossa Valley may be of betterknown origin for Shiraz among the respondents. Regarding of wine ROO, Wine Intelligence (2012) has undertaken ROO awareness market research among 1,001 Chinese upper middle - class imported wine drinkers. Surprisingly, market research has revealed that the France Rhone Valley had the third highest rank with 42\% however Australia Barossa Valley had only the eighth rank with 29\%. This finding tells us France Rhone Valley is better known to Chinese wine consumers than Australia Barossa Valley, which is different from the present study results.

For Australian Barossa Shiraz, 'Chocolate' (43/ 53.1\%) and 'Jammy' (36/53.7\%) were the two most marked sensory images and 'Full body'
(67/ 47\%), 'Prune’ (46/ 43.4\%), 'Plum' (36/ 46\%), 'Thick' (69/45\%), 'Strong' (54/ 45.4\%), 'Masculine' (51/ 43.2\%) and 'Heavy' (62/ 44.9\%) were highly marked sensory images. For French Rhone Syrah, 'Fascinating' (55.1\%) and 'Stately' (53.5\%) were the two most distinctive images. In addition to these, 'Black pepper' (55/ 42.3\%), 'Characterful' (38/ 49.4\%), 'Deep' (39/ 48.1\%) and 'Medium body' (45/46.9\%) were defined as distinctive sensory images for French Rhone Syrah. However, there were no significantly marked sensory images for Chilean Maipo Syrah. Not surprisingly, this result indicates that Korean respondents do not have distinctive sensory associations with Chilean Maipo Syrah, thus this study confirms that Chile Maipo is not recognizable ROO for Syrah. Furthermore, it is suggested that sensory images are not attractive marketing communication tool to promote Chilean Maipo Syrah in Korea. A further suggestion, focusing on non - sensory aspects such as price and brand, could be applied into marketing promotion and advertising strategies for Chilean Maipo Syrah. Interestingly, between 


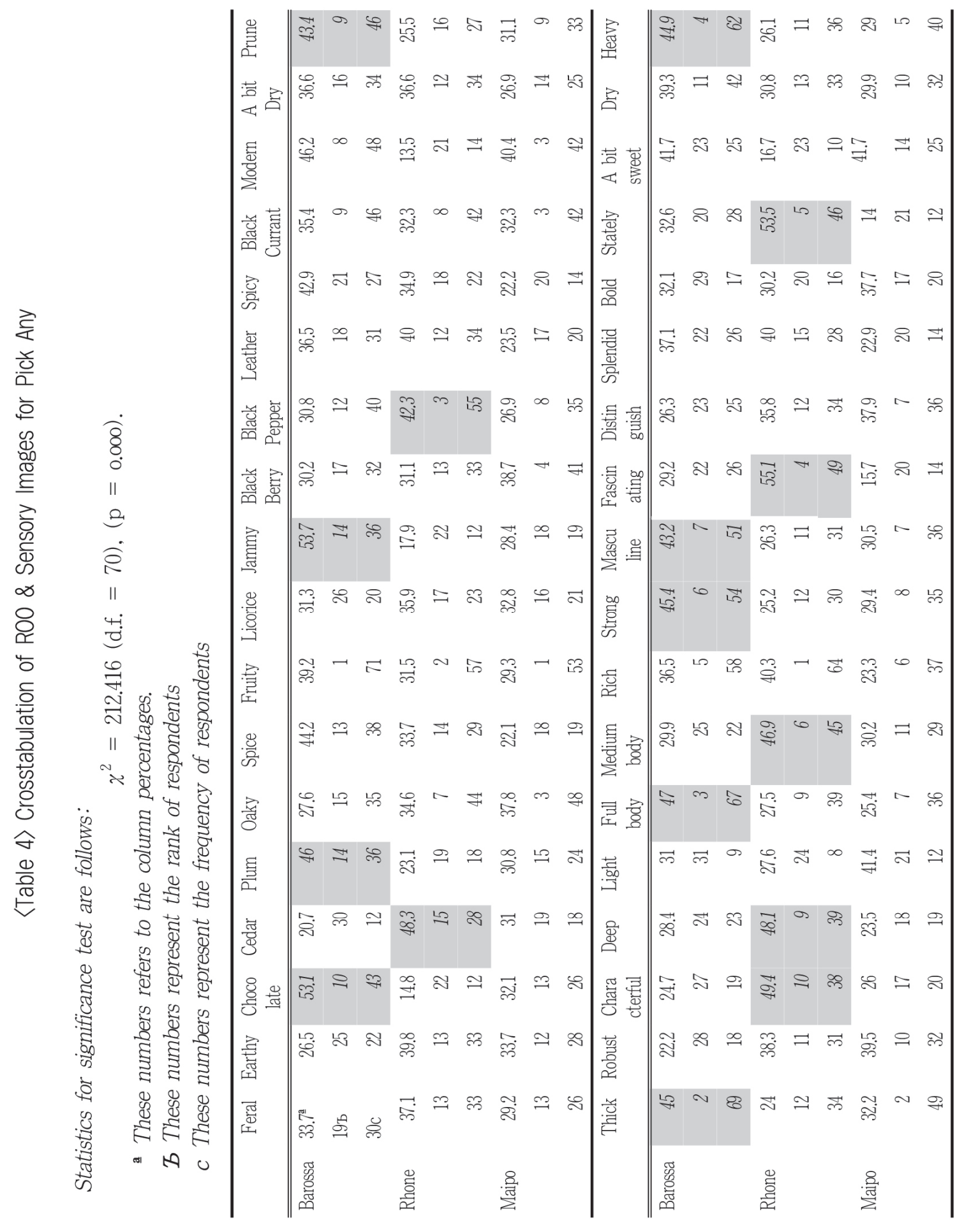


Barossa and Rhone 'A bit dry' (34/ 36.6\%) was found with same frequency of association, and 'A bit sweet' (25/ 41.7\%) had same frequency data for Barossa and Maipo.

\subsection{Wine sensory image correspondence analysis}

Table 5a shows the dimensions as well as the row points (ROO) and the column points (sensory images) achieved by the correspondence analysis. The proportion of explained inertia indicates the percentage value of the inertia given by each dimension (Berenguer et al 2009). Particularly, as evidenced from Table $5 \mathrm{a}$, the first and second dimensions of the correspondence analysis accounted for $100 \%$ of model variance, representing $74.2 \%$ (first dimension) of the $\mathrm{ex}^{-}$ plained variance and 25.8\% (the second) of explained variance, respectively. Table $5 \mathrm{~b} \mathrm{de}^{-}$ scribes the contributing sensory images to each dimension. The first dimension loads 26 out of 36 sensory images and 10 sensory images are loaded in the second dimension. This result shows the 26 sensory images shared a commonality in the first dimension and the second dimension was described by 10 images. As the second dimension had a low singular value $(<0.20)$, the correspondence analysis on sensory images associated with ROOs of Shiraz/ Syrah determines one dimensional solution. For that reason, the respondents' sensory images of Shiraz/ Syrah can better be explained by the first dimension. As a result, this study excludes the 10 sensory images loaded on the second dimension, namely 'Licorice', 'Light body', 'Black berry', 'Robust', 'Bold,, 'Spicy', 'Black currant', 'Distinguish', 'Oaky', and 'Spice' from further analyses.

Based on the outcome of the chi-square value, differences were considered highly significant when $\mathrm{p} \leq 0.000$. As reflected in the significance test of $\chi^{2}$ - statistic (see Table 4), the each ROO for Shiraz/ Syrah generally converge with their sensory images which show a positive relationship between the two category variables (see Figure 1). Obviously, such a result is to be expected since Australia and France have their own unique sensory images as a wellknown ROO of Shiraz/ Syrah. Consequently, since there were groups of ROO and associated

$\langle$ TABLE 5a〉 Correspondence Analysis Results a

\begin{tabular}{c|c|c|c|c|c|c|c|c}
\hline \multirow{2}{*}{ Dimension } & \multirow{2}{*}{$\begin{array}{c}\text { Singular } \\
\text { Value }\end{array}$} & Inertia & \multirow{2}{*}{$\begin{array}{c}\text { Chi } \\
\text { Square }\end{array}$} & \multirow{2}{*}{\begin{tabular}{c} 
Sig. \\
\cline { 5 - 8 }
\end{tabular}} & $\begin{array}{c}\text { Accounted } \\
\text { for }\end{array}$ & Cumulative & $\begin{array}{c}\text { Proportion of Inertia } \\
\text { Deviation }\end{array}$ & \multicolumn{2}{c}{ Confidence Singular Value } \\
\hline \hline 1 & .213 & .045 & & & .742 & .742 & .016 & -.025 \\
2 & .126 & .016 & & & .258 & 1.000 & .017 & \\
\hline Total & & .061 & 212.416 & .000 & 1.000 & 1.000 & & \\
\hline
\end{tabular}


〈Table 5b〉 Correspondence Analysis Results b

\begin{tabular}{|c|c|c|c|c|c|c|c|c|c|}
\hline & \multirow{3}{*}{ Mass } & \multicolumn{2}{|c|}{ Score in Dimension } & \multirow{3}{*}{ Inertia } & \multicolumn{5}{|c|}{ Contribution } \\
\hline & & \multirow[t]{2}{*}{1} & \multirow[t]{2}{*}{2} & & \multicolumn{2}{|c|}{$\begin{array}{l}\text { Of Point to Inertia } \\
\text { of Dimension }\end{array}$} & \multicolumn{3}{|c|}{$\begin{array}{c}\text { Of Dimension to Inertia } \\
\text { of Point }\end{array}$} \\
\hline & & & & & 1 & 2 & 1 & 2 & Total \\
\hline \multicolumn{10}{|l|}{ Row Points } \\
\hline Barossa & .370 & -.412 & .338 & .019 & .295 & .336 & .716 & .284 & 1.000 \\
\hline Rhone & .333 & .642 & .090 & .030 & .645 & .021 & .989 & .011 & 1.000 \\
\hline Maipo & .297 & -.208 & -.521 & .013 & .060 & .643 & .212 & .788 & 1.000 \\
\hline \multicolumn{10}{|l|}{ Column Points } \\
\hline Heavy & .040 & $\begin{array}{l}-.366 \\
\end{array}$ & .191 & .001 & .025 & .012 & .861 & .139 & 1.000 \\
\hline Licorice & .018 & .159 & -.265 & .000 & .002 & .010 & .378 & .622 & 1.000 \\
\hline Stately & .025 & .847 & .679 & .005 & .083 & .091 & .725 & .275 & 1.000 \\
\hline Modern & .030 & -.882 & -.340 & .005 & .109 & .027 & .919 & .081 & 1.000 \\
\hline Light body & .008 & -.173 & -.687 & .001 & .001 & .031 & .097 & .903 & 1.000 \\
\hline Jammy & .019 & -.776 & .395 & .003 & .055 & .024 & .867 & .133 & 1.000 \\
\hline Black berry & .030 & -.023 & -.572 & .001 & .000 & .079 & .003 & .997 & 1.000 \\
\hline Black pepper & .037 & .418 & .012 & .001 & .031 & .000 & 1.000 & .000 & 1.000 \\
\hline Rich & .046 & .281 & .303 & .001 & .017 & .033 & .594 & .406 & 1.000 \\
\hline Feral & .026 & .181 & -.041 & .000 & .004 & .000 & .970 & .030 & 1.000 \\
\hline Robust & .023 & .339 & -.769 & .002 & .013 & .110 & .247 & .753 & 1.000 \\
\hline Bold & .015 & -.079 & -.489 & .000 & .000 & .029 & .042 & .958 & 1.000 \\
\hline Strong & .034 & -.405 & .179 & .001 & .026 & .009 & .896 & .104 & 1.000 \\
\hline Earthy & .024 & .357 & -.404 & .001 & .014 & .031 & .570 & .430 & 1.000 \\
\hline Chocolate & .023 & -.894 & .200 & .004 & .087 & .007 & .971 & .029 & 1.000 \\
\hline Leather & .024 & .271 & .290 & .001 & .008 & .016 & .597 & .403 & 1.000 \\
\hline Spicy & .018 & .007 & .480 & .001 & .000 & .033 & .000 & 1.000 & 1.000 \\
\hline Black currant & .037 & -.026 & -.159 & .000 & .000 & .008 & .042 & .958 & 1.000 \\
\hline Prune & .030 & -.375 & .056 & .001 & .020 & .001 & .987 & .013 & 1.000 \\
\hline A bit sweet & .017 & -.710 & -.491 & .002 & .041 & .033 & .780 & .220 & 1.000 \\
\hline Cedar & .017 & .753 & -.387 & .002 & .044 & .020 & .865 & .135 & 1.000 \\
\hline Splendid & .020 & .265 & .336 & .001 & .007 & .018 & .513 & .487 & 1.000 \\
\hline Plum & .022 & -.498 & .128 & .001 & .026 & .003 & .962 & .038 & 1.000 \\
\hline Deep & .023 & .674 & .134 & .002 & .050 & .003 & .977 & .023 & 1.000 \\
\hline Distinguish & .027 & .200 & -.610 & .002 & .005 & .081 & .154 & .846 & 1.000 \\
\hline Full body & .041 & -.332 & .412 & .002 & .021 & .055 & .524 & .476 & 1.000 \\
\hline A bit dry & .027 & .133 & .128 & .000 & .002 & .004 & .645 & .355 & 1.000 \\
\hline Oaky & .036 & .143 & -.581 & .002 & .003 & .098 & .093 & .907 & 1.000 \\
\hline Spice & .025 & -.054 & .512 & .001 & .000 & .052 & .018 & .982 & 1.000 \\
\hline Fruity & .052 & -.095 & .064 & .000 & .002 & .002 & .789 & .211 & 1.000 \\
\hline Characterful & .022 & .758 & -.062 & .003 & .060 & .001 & .996 & .004 & 1.000 \\
\hline Masculine & .034 & -.342 & .083 & .001 & .019 & .002 & .966 & .034 & 1.000 \\
\hline Thick & .044 & -.519 & .042 & .003 & .055 & .001 & .996 & .004 & 1.000 \\
\hline Medium body & .028 & .676 & -.303 & .003 & .059 & .020 & .894 & .106 & 1.000 \\
\hline Dry & .031 & -.121 & .034 & .000 & .002 & .000 & .955 & .045 & 1.000 \\
\hline Fascinating & .026 & .942 & .526 & .006 & .107 & .056 & .844 & .156 & 1.000 \\
\hline
\end{tabular}


sensory images that differed in relation to perceptual space, the total structure displayed significant perceptual heterogeneity. To extract the most two common sensory images for Shiraz/ Syrah, this study defined dashed circle (see Figure 1). As evidenced from FIGURE1, the most two common images were 'Fruity' and 'Dry'. 'A bit dry' and 'Feral' lie just outside of dashed circle. With the deep insight into this finding, this study could infer actually these images 'Fruity' and 'Dry' mean the lowest level of association of sensory images of Shiraz/ Syrah among Korean respondents. It might be also carefully assumable that some less involved respondents randomly picked up any images generally represent Australian, French or Chilean red grape variety.

\subsection{Aroma Vs Overall images}

As shown in Figure 1, sensory images of Barossa Shiraz converge on the left side of the axis while Rhone Syrah images lie in the right side. The vertical axis of dimension one separates 'Chocolate' on the left from 'Fascinating' on the right. In order to know how dissimilarly/ similarly Korean wine consumers perceive the Shiraz/ Syrah of different ROO for different sensory image categories, this study separately shows plots of sensory images by correspondence analysis Figure 2 for Aroma images, Figure 3 for Overall images and Figure

〈Figure 1〉 Wine Sensory Images Correspondence Analysis

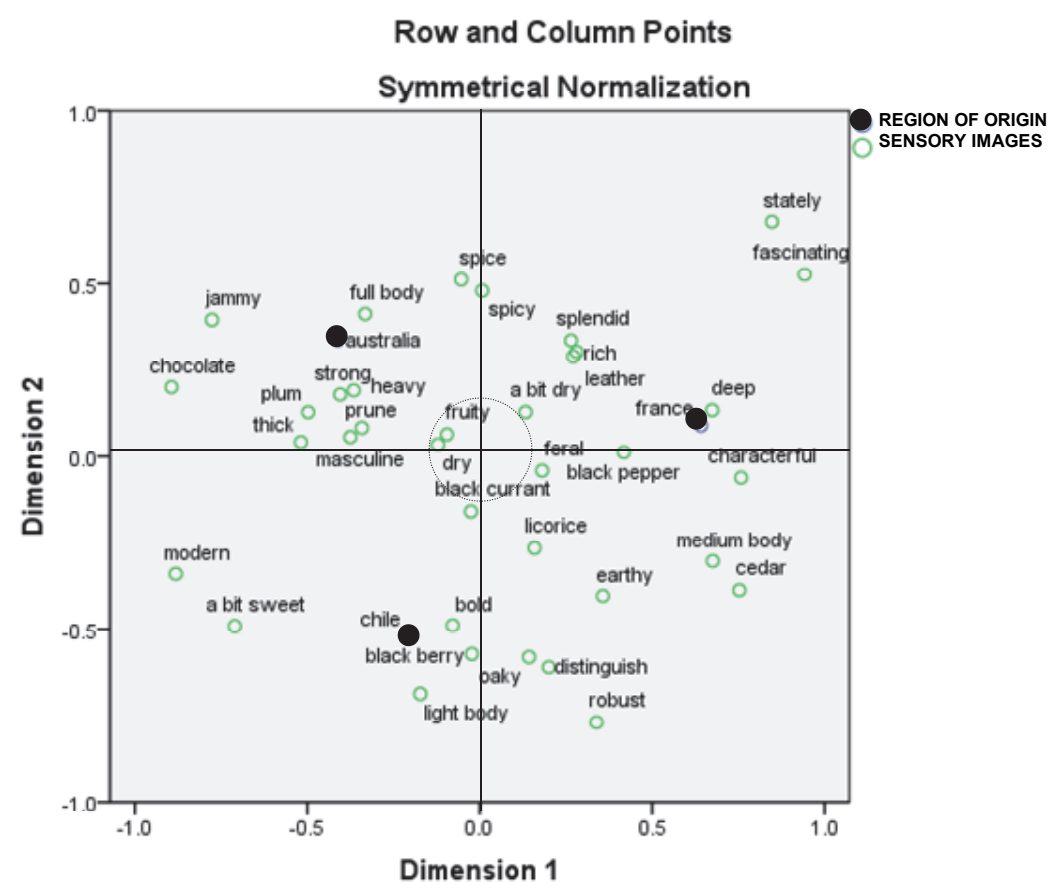

Shiraz Vs Syrah Crafting Advertising Campaign, using Sensory Images 115 
4 for Body \& Sweetness images. According to the Figure2, Barossa Shiraz apparently has more marked aroma images ('Chocolate', 'Plum, 'Prune', and 'Jammy') than French Syrah ('Black pepper') within aroma category. Within Overall image category (see Figure 3), compared to aroma image category, French Syrah had more differentiated images 'Fascinating,, 'Stately', 'Deep’, and 'Characterful' and Australian Shiraz had more closely associated images such as 'Masculine', 'Strong', 'Thick' and 'Heavy.' It is well known that aroma images represent olfactory characteristics of wine, whereas overall images represent general feelings and impressions of wine, and they are difficult to define and almost impossible to present accurately. In summary, it could be argued that Barossa Shiraz might be easier to be differentiated with aromas of Shiraz, while French Syrah might be better differentiated with overall images among Koreans.
Importantly, this finding implicitly suggests promotion/ regional campaigns of Barossa Shiraz should promote unique aroma images of Shiraz adding some overall images of Shiraz, while French Rhone should promote unique overall images.

Interestingly, the author found that two most common images 'Fruity' and 'Feral' (see dashed circle in Figure 2) across the three countries, whereas no common overall images lie inside of dashed circle in Figure 3. Accordingly, it could be interpreted that among Korean respondents 'Fruity' and 'Feral' are perceived as the most two shared primary sensory images of Shiraz/ Syrah, regardless of ROOs. In further contrast with the pattern of distribution shown in Figure 2, most of images in Figure 3 were skewed towards their own ROO. Therefore, it is highly emphasized that overall images have stronger attachment towards each ROO (see Figure 3),

〈Figure 2〉 Aroma Images Correspondence Analysis

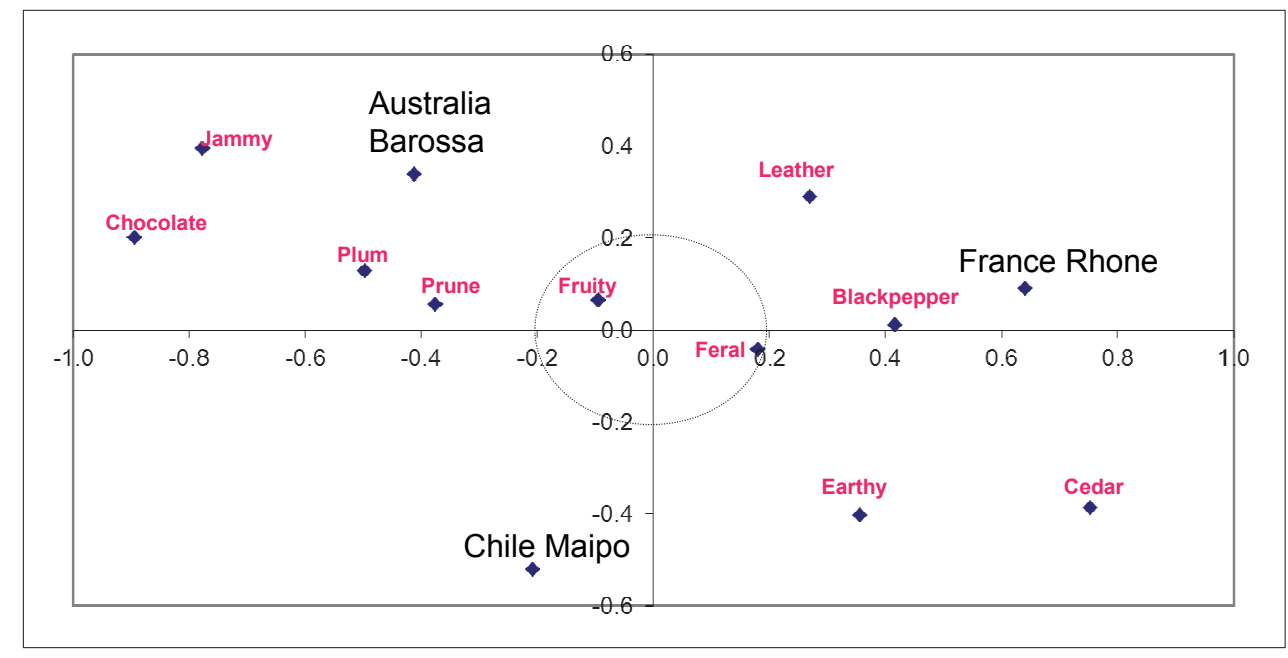

116 ASIA MARKETING JOURNAL Vol. 18 No. 04 January 2017 
〈Figure 3〉 Overall Images Correspondence Analysis

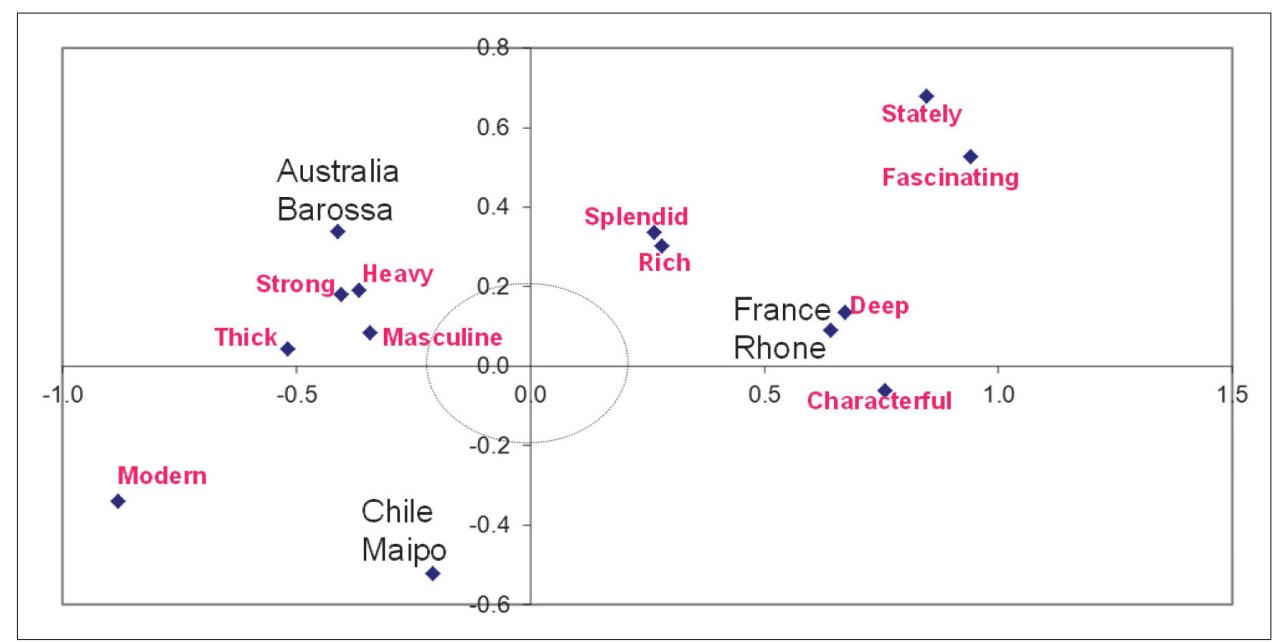

in comparison to aroma images (see Figure 2). This finding indicates that the respondents had a clear distinction between Shiraz and Syrah in terms of overall images, whereas they showed little evident distinction of aroma images between Shiraz and Syrah. This might be due to the difficulty in understanding aroma terms for Koreans e.g. 'Licorice', 'Cedar', whereas overall images are relatively easier to understand for them e.g. 'Heavy', 'Rich', etc.

\subsection{Body Vs Sweetness images}

Figure 4 provides a graphic representation of the relative positions of the three ROOs of Shiraz/ Syrah and body and sweetness images derived from the correspondence analysis. As depicted in FIGURE4, it is obviously concluded that each body image associated with its own ROO. For example, 'Full body' is closely at- tached to Australian Shiraz and 'Medium body' is closely associated with French Syrah. As discussed earlier in this paper, it is once again confirmed that 'Dry' and 'A bit dry' were relatively perceived as primary shared sensory images of Shiraz/ Syrah across the three ROOs, although 'Dry' was a little bit more closely associated with Australian Shiraz. In addition, 'A bit sweet' was perceived as the shared image for Australia and Chile among the respondents. In conclusion, this study shows that Australian Shiraz is mainly differentiated with aroma images of Shiraz whereas French Syrah is mainly differentiated with overall images of Syrah. Also the author found that overall images of Shiraz/ Syrah showed much stronger associations towards each $\mathrm{ROO}$ than aroma image attributes. In addition to this, body images closely are attached to their own ROO. 
〈Figure 4〉 Body \& Sweetness images Correspondence Analysis

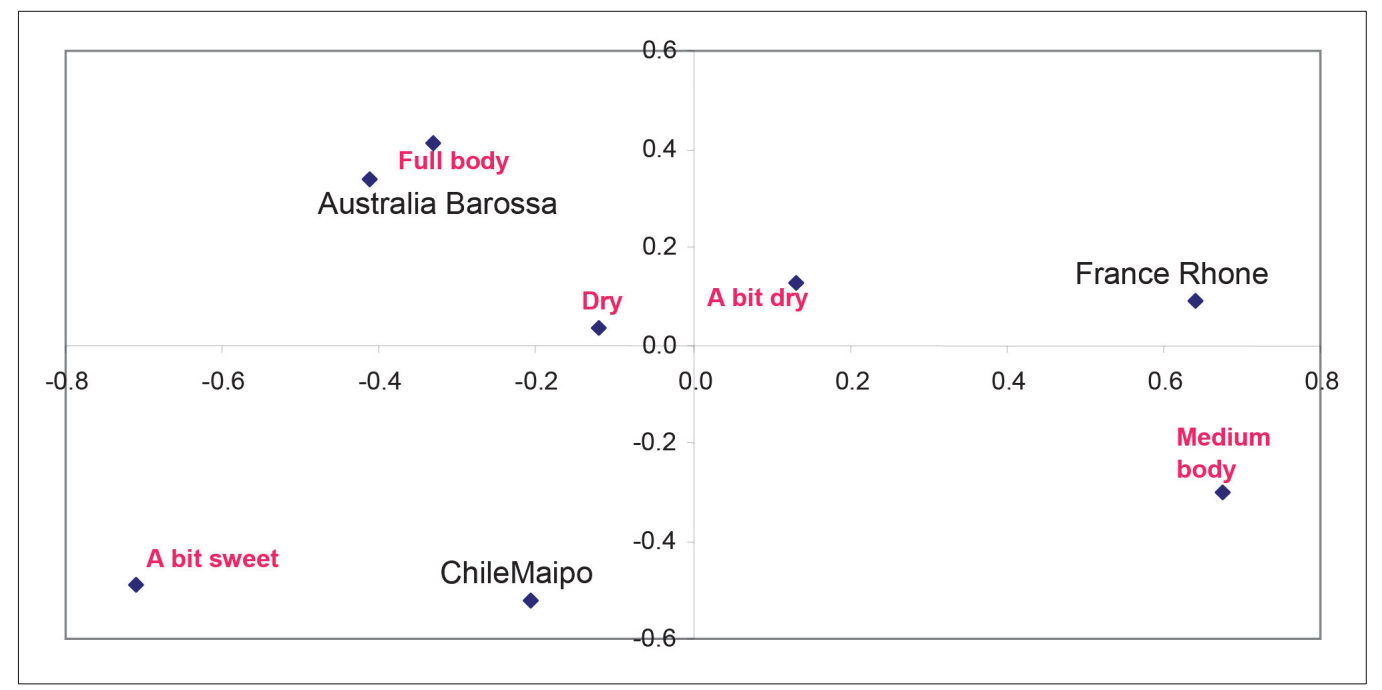

\section{Market Implications}

Wine marketers should know consumer trend and have to set up a marketing strategy following by consumer trends but also sometimes marketers themselves should predict, create and lead new consumer trends. There is no doubt that an advertising campaign is one of the most effective strategies to create consumer trends, in particular introducing new and unfamiliar products. "What wine marketers and academics can do with sensory images?" Firstly, this study will provide a more theoretical basis of sensory research for marketing communication from the wine consumer points of view. Further this research framework will help them to develop another approach of consumer oriented market research, using sensory images. Also, they can consider applying this type of research into other food and beverage products. Secondly, for wine practitioners, including retailers and restaurateurs, this study may be a considerable guide in how to apply sensory images into an advertising campaign and how to make them successful and profitable in the actual marketplace. Also, wine producers may consider re - positioning or re - branding their wines in the export markets by utilizing sensory images. Here, the author proposes the conceptualization of advertising campaign of Australian Barossa Shiraz in Korean wine market as an example, using sensory images derived from the results. According to Figure 3, overall images closely attached to Australian Shiraz are; 'Thick' - 'Full body' 'Heavy' - 'Strong' - 'Masculine'. Then we can extract one key message represent these five images; that is 'Dark' (see Figure 5). According 
to Figure 2, the most unique aroma image for Australian Shiraz is 'Chocolate'. Based on this finding, the author designs the advertising campaign for Barossa Shiraz in Korea, adding one key message, namely 'Dark' (see Figure 5) into 'Chocolate'; 'Dark Chocolate, the taste of Barossa Shiraz'. This study recommends that designing advertising campaigns, marketers should apply different types of images into different ROO of grape varieties. For example, in an attempt to attract potential Korean wine consumers of French Rhone Syrah, advertising campaigns should utilize overall images of French Syrah such as 'Deep Valley, Fascinating Rhone’, whereas for Australian Shiraz they can persuade customers describing aroma images of Barossa Shiraz. In summary, it is clear that wine marketers have to know and use consumers' specific sensory images which are associated with the identity of the grape variety through accurate market intelligence. As well the resulting data may be particularly useful for developing competitive marketing plans for wine exporters targeting Korean wine consumers. Better understanding of Korean wine consumers' sensory perceptions in their minds would greatly contribute in penetrating the Korean wine market in popularizing wines among Korean wine consumers.

\section{Limitations \& Future Research}

Although this study has provided important information, the limitation of this study is its exploratory nature. Applying advertising campaign strategy into individual wine brand, there would has a huge task to cover each different wine brand, using sensory images. Maybe, lowprice Australian Barossa Shiraz obviously presents 'Black pepper' but high-price Australian Barossa Shiraz presents 'Dark Chocolate'. In

〈Figure 5〉 The Conceptualization of Wine Regional Advertising Campaign For Barossa Valley Shiraz 'Dark Chocolate, the Taste of Barossa Shiraz'

\section{Thick}

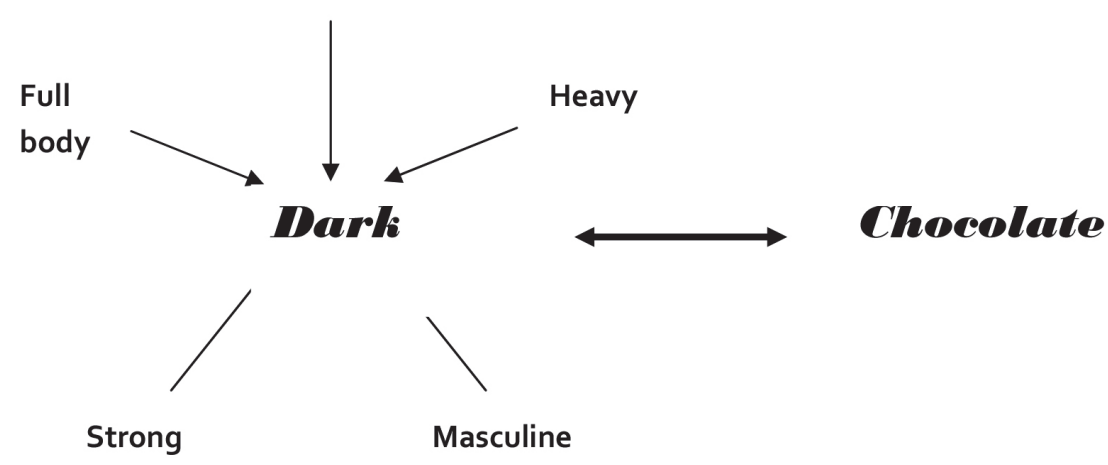


fact, this study has conducted within one city, Seoul. In addition, the respondents were mainly from online wine community members, and majority of respondents were not married. As the shortage of data collection, the results still have shown some limitations, only implementing within relatively high involved wine consumers, mainly drinking higher price wine. Hence, more research is necessary to be done with a larger scale of sample. Then the results would be more generalized and popularized, being able to apply into relatively more average wine consumers.

This study has been done with red grape variety 'Shiraz/ Syrah' and chosen Australia, France, and Chile as COOs. A further study might consider another choice set of $\mathrm{COO} / \mathrm{ROO}$ with another choice of criteria, such as wine style, climate, etc. for instance, Champagne Vs Sparkling, German Riesling Vs Alsace Riesling. For the better implication of wine regional advertising campaign, future research is also obviously necessary to explore not only sensory images but also other images, such as place, heritage, landscape, etc.

〈Received February 8. 2017〉

〈Revised February 8. 2017〉

〈Accepted February 12. 2017〉

\section{References}

Aaker, D. A. 1992. The value of brand equity. Journal of Business Strategy, 13(4).

Anderson, J. R., and Bower, G. H. 1979. Human Associative Memory, Hillsdale: Lawrence Erlbaum.

Ares, G., A. Giménez, and A. Gámbaro.2008a. Understanding consumers' perception of conventional and functional yogurts using hard laddering and word association. Food Quality and Preference, 19, 636-643

Atkin, T., R. Garcia, and L. Lockshin. 2005. Adaptation of wine innovation. Paper presented at the 2nd Annnual International Wine Marketing Symposium, Sonoma State University, Sonoma.

Barnard, N. R., P. T. Barwise and A. S. C. Ehrenberg. 1986. Reinterview in attitude research: early results. MRS Conference, Brighton: Market Research Society.

Berenguer, G., I. Gil, and M. Ruiz. 2009. Do upscale restaurant owners use wine lists as a differentiation strategy? International Journal of Hospitality Management, 28: 86-95.

Boudreaux, C. A., and S. E. Palmer, 2007. A charming little Cabernet: Effects of wine label design on purchase intent and brand personality. International Journal of Wine Business Research, 19(3): 170-186.

Bruwer, J. 2007. Advanced wine marketing. 
Unpublished study guide. The University of Adelaide, Adelaide.

Bruwer, J. and T. Johnson. 2005. The drivers of on-premises beverage selection in Australia. http://www.wineaustralia.com/winefacts/

Cartier, R., Rytz, A., Lecomte, A., Poblete, F., Krystlik, J., Belin, E., and Martin, N. 2006. Sorting procedure as an alternative to quantitative descriptive analysis to obtain a product sensory map. Food Quality and Preference, 17: 562-571.

Corsi, A. M., S. Mueller, and L. Lockshin. 2012. Let's see what they have $\cdots$ : What consumers look for in a restaurant wine list. Cornell Hospitality Quarterly. Online first published on 27 Jan 2012.

d'Hauteville, F. 2003.Communicating on the sensory quality of wine: Questions about sensory training and expertise. Paper presented at the 1st International Wine Marketing Colloquium, University of South Australia, Adelaide.

Dillon, W. R., Maddern, T. J., Kirmani, A. and Mukherjee, S. 2001. Understanding what's in a brand rating: a model for assessing brand and attribute effects and their relationship to brand equity. Journal of Marketing Research, 38(4): 415-429.

Dooley, L., Y. Lee, and J. Meullenet. 2010. The application of check-all-that-apply (CATA) consumer profiling to preference mapping of vanilla ice cream and its comparison to classical external preference mapping. Food
Quality and Preferenc, 21: 394-401.

Driesener, C., and J. Romaniuk. 2006. Comparing methods of brand image measurement. International Journal of Market Research, 48(6) : 681-698.

Elliot, S., and J.E. (Joe) Barth. 2012. Wine label design and personality preferences of millennials. Journal of Product \& Brand Management, 21(3) : 183-191

Enneking, U., C. Neumann, and S. Henneberg. 2007. How important intrinsic and extrinsic product attributes affect purchase decision. Food Quality and Preference, 18: 133-138 Faye, P., D. Bremaud, M. D. Daubin, P. Courcoux, A. Giboreau and H. Nicod. 2004. Food Quality and Preference, 15: 781-791.

Gawel, R., P. G. Iland, and I. L. Francis. 2001. Characterizing the astringency of red wine: a case study. Food Quality and Preference, 12: 83-94.

Iland, P. and P. Gago. 2005. Australian wine styles and taste. Adelaide, SA: Patrick Iland Wine Promotions.

Johnson, R., and J. Bruwer. 2007. Regional brand image and perceived wine quality: the consumer perspective. International Journal of Wine Business Research, 19(4): 276-297. Joyce, T. 1963. Techniques of Brand Image Measurement. New Developments in $\mathrm{Re}^{-}$ search. Market Research Society, 45-63.

Keller, K. L. 2003. Brand Synthesis: The multidimentionality of Brand Knowledge. Journal of Consumer Research, 29(Mar): 595-601. 
Labroo, Aparna A., Ravi Dhar, and Norbert Schwarz. 2008. Of frog wines and frowning watches: Semantic priming, perceptual fluency, and brand evaluations. Journal of Consumer Research, 34 (April): 819-31.

La Tour, K. A., M. S. La Tour, and A. H. Feinstein. 2011. The effects of perceptual and conceptual training on novice wine drinkers' development. Cornell Hospitality Quarterly, 52 (4): 445-457.

Lim. J., and H. T. Lawless. 2005. Qualitative differences of divalents salts: multidimensional scaling and cluster analysis. Chemical Senses, 30: 719-726.

McEwan, J. A., and P. Schich. 1992. Correspondence analysis in sensory evaluation, Food Quality and Preference, 3: 23-36.

Moskowitz, H., J. Beckley, and J. Adams. 2002. What makes people crave fast foods? Nutrition Today, 37(6): 237-242.

Myers, C. A. 2003. Managing brand equity: a look at the impact of attributes. Journal of Product \& Brand Management, 12(1): 39-51.

Meyers-Levy, J. 1989. The influence of a brand name's association set size and word frequency on brand evaluations. Journal of Consumer Research, 17: 263-276.

Panea, B., I. Casasus, M. Blanco, and M. Joy. 2009. The use of correspondence analysis in the study of beef quality: a case study on Parda de Montana breed. Spanish Journal of Agricultural Research, 7 (4): 876-885.
Perrouty, J. P., F. d'Hauteville. and L. Lockshin. 2007. The influence of wine attributes on region of origin equity: an analysis of the moderating effect of consumer's perceived expertise. Agribusiness, 22(3): 323-341.

Puyares, V., G. Ares, and F. Carrau. 2010. Searching a specific bottle for Tannatwine using a check-all-that apply question and conjoint analysis. Food Quality and Preference, 21: $684-691$.

Romaniuk, J., and B. Sharp. 2003. Measuring brand perceptions: Testing quantity and quality. Journal of Targeting, Measurement and Analysis for Marketing, 11(3): 218-229.

Schamel, G. 2006. Geography versus brands in a global wine market. Agribusiness, 22(3): 363-374.

Sinesio, F., E. Moneta, M. Peparaio, and M. Esti. 2005. Exploring sensory properties of FrascatiSuperiore CDO wine using Correspondence Analysis, in: Proceeding of VI Pangborn Sensory Science Symposium, Harrogate, North Yorkshire, UK.

Torres, A., and M. Greenacre. 2002. Dual scaling and correspondence analysis of preferences, paired comparisons and ratings. International Journal of Research in Marketing, 19: 401405.

Torres, A., and M. van de Velden. 2007. Perceptual mapping of multiple variable batteries by plotting supplementary variables in correspondence analysis of rating data. Food Quality and Preference, 18(1): 121-129. 
Tversky, A. 1972. Elimination by aspects: A theory of choice. Psychological Review, 79 (4) : 281-299.

Wine and Spirit Education Trust. 2005. Wines and Spirits looking behind the label. London, UK: Wine \& Spirit Education Trust.

Vickers, Z. M. 1993. Incorporating tasting into a conjoint analysis of taste, health claim, price and brand for purchasing strawberry yogurt. Journal of Sensory Studies, 8: 341352.

http://gain.fas.usda.gov/Recent\%20GAIN\%20 Publications/Wine\%20Market\%20Report Seoul\%20ATO_Korea\%20-\%20Republic $\% 20$ of_9-8-2016.pdf accessed on $20^{\text {th }}$ of December, 2016
http://gain.fas.usda.gov/Recent\%20GAIN\%20 Publications/Wine\%20Market $\% 20$ Brief $\% 20$ 2012_Seoul\%20ATO_Korea\%20-\%20 Republic\%20of_8-24-2012.pdf accessed on 8th of December, 2012

http://www.wineintelligence.com/wp-content/ uploads/White-Paper-Global-wine-market -evaluation-model.pdf accessed on 7th of July, 2011.

http://www.wineintelligence.com/wp-content/ uploads/Wine-Intelligence-Adhesion-group -White-paper-21-2-2012.pdf accessed on 12th of March, 2012.

http://www.wineintelligence.com/reports-shop/ products-page/south-korea/china-and-south -korea-market-overview/accessed on 8th of December, 2012. 


\section{〈Appendix A〉 8 wine experts who participated in the preliminary study}

\begin{tabular}{|c|l|l|l|}
\hline & \multicolumn{1}{|c|}{ Name } & \multicolumn{2}{|c|}{ Job Position } \\
\hline 1 & Sun-Kyung LEE & Hotel Silla & Sommelier \\
\hline 2 & Jin-Kyu KIM & Wine Shop, Cepdor (Myungdong) & Shop Manager \\
\hline 3 & Kyung-Tae PARK & Wine Bar, Claret & Sommelier \\
\hline 4 & Hee-Seok OH & Wine Restaurant, Molto & Sommelier \\
\hline 5 & Jae-Youn KO & Kyung Hee University & Professor \\
\hline 6 & Hyun-Mo JUN & GyeongJu University & Professor \\
\hline 7 & Sang- Ho MAENG & Online Wine Community 'Wine N Joy' & $3^{\text {rd }}$ Manager \\
\hline 8 & Ji-Sun SONG & Online Wine Community 'Wine N Joy' & $1^{\text {st }}$ Founder \\
\hline
\end{tabular}

\section{$\langle$ Appendix B〉}

\begin{tabular}{|c|l|c|l|c|}
\hline Rank & \multicolumn{1}{|c|}{$\begin{array}{c}\text { 16 Aroma } \\
\text { Images }\end{array}$} & $\begin{array}{c}\text { No. of } \\
\text { Freq }\end{array}$ & \multicolumn{1}{|c|}{$\begin{array}{c}\text { 14 Overall } \\
\text { Images }\end{array}$} & $\begin{array}{c}\text { No. of } \\
\text { Freq }\end{array}$ \\
\hline 1 & Black pepper & 31 & Thick, Heavy & 26 \\
\hline 2 & Black berry & 24 & Masculine & 23 \\
\hline 3 & Spice & 23 & Strong & 22 \\
\hline 4 & Spicy & 22 & Characterful & 15 \\
\hline 5 & Black Currant & 21 & Stately & 14 \\
\hline 6 & Fruity & 20 & Rich, Deep & 12 \\
\hline 7 & Licorice & 18 & Splendid, Distinguish & 11 \\
\hline 8 & Oaky, Chocolate & 17 & Robust, Fascinating, Bold, Modern & \\
\hline 9 & Leather, Jammy, Prune & 16 & & \\
\hline 10 & Cedar & 14 & & \\
\hline 11 & Feral, Plum, Earthy & 13 & & \\
\hline
\end{tabular}

